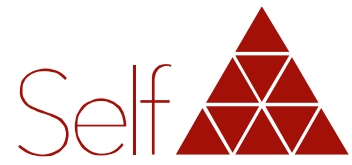

Revista do Instituto Junguiano de Săo Paulo

\title{
A experiência amorosa como rito de passagem dentro do processo de individuação feminino
}

\section{Ana Lúcia CIRINEU}

São Paulo, SP, Brasil.

\section{Resumo}

presente trabalho teve como objetivo refletir sobre a experiência amorosa tal como ela é vivida pelas mulheres, ressaltando essa trajetória como um processo único e de grande importância no desenvolvimento da psique feminina. A escolha por analisar especificamente a experiência amorosa feminina partiu do pressuposto de que ela se dá de forma diferente daquela do desenvolvimento masculino. Na mulher, o amor configura-se como um rito iniciático que a coloca na jornada da individuação, já o homem, no decorrer de seu desenvolvimento, depara-se com outras formas de iniciação. A pesquisa aqui desenvolvida investigou de que forma a experiência amorosa serve como rito de passagem para o caminho de individuação feminino, explorando mais precisamente o sofrimento enquanto marca principal desse rito de passagem. A partir do mito de Eros e Psiquê, analisou-se o caminho

Conflito de interesses:

A autora declara não haver nenhum interesse profissional ou pessoal que possa gerar conflito de interesses em relação a este manuscrito. percorrido pela mulher na descoberta de si mesma, considerando o sofrimento experimentado no decorrer do processo como necessário e facilitador do encontro com o animus, o que, consequentemente, contribui para o processo de tomada de consciência e para a busca autônoma da individuação feminina.

\section{Descritores}

amor, ritos de iniciação, sofrimento, individuação (psicologia).

Recebido: 2 mar 2020; $1^{\text {a }}$ revisão: 5 maio 2020; Aprovado: 16 out 2020; Aprovado para publicação: 26 out 2020 


\title{
The experience of love as rite of passage within the feminine individuation process
}

\begin{abstract}
This paper aimed to reflect on the experience of love as woman lives it, highlighting this trajectory as a unique process of great importance in the development of the feminine psyche. The specific choice of analyzing the feminine experience of love has departed from the presupposition that it is different from the experience of the masculine development. In woman, love is configured as an initiation rite that situates them in the journey of individuation, while man finds other ways of initiation at the course of their development. This research has investigated in what way the experience of love is as rite of passage in the path to feminine individuation, exploring more precisely suffering as the hallmark of this rite. From the myth of Eros and Psyche the path walked by the woman in the discovery of herself was analyzed, considering suffering as necessary and a facilitator of the encounter with the animus, which therefore contributes to the process of awareness, and to the autonomous search of feminine individuation.
\end{abstract}

\section{Descriptors}

love, initiation rites, suffering, individuation (psychology).

\section{La experiencia amorosa como rito de pasaje dentro del proceso de individuación femenino}

\section{Resumen}

Este trabajo tuvo como objetivo analizar la experiencia amorosa tal como la viven las mujeres, destacando esta trayectoria como un proceso único y de gran importancia en el desarrollo de la psiquis femenina. La decisión de investigar específicamente la experiencia amorosa femenina parte de la presuposición de que ésta ocurre de forma diferente a la del desarrollo masculino. En la mujer, el amor se configura como un rito iniciático que la coloca en la jornada de la individuación; el hombre, en el transcurso de su desarrollo, encuentra otras formas de iniciación. La investigación desarrollada aquí procura analizar de qué forma la experiencia amorosa sirve como rito de paso para el camino de individuación femenino, examinando más precisamente el sufrimiento como hito principal de este rito de paso. A partir del mito de Eros y Psique se analizó el camino recorrido por la mujer en el descubrimiento de sí misma, considerando el sufrimiento experimentado en el 
trascurso del proceso como necesario y propiciador del encuentro con el animus, lo que, consecuentemente, contribuye al proceso de toma de consciencia y a la búsqueda autónoma de la individuación femenina.

\section{Descriptores}

amor, ritos de iniciación, sufrimiento, individuación (psicología).

\section{Introdução}

O presente trabalho teve como objetivo analisar a experiência amorosa tal como ela é vivida pelas mulheres, ressaltando essa trajetória como um processo único e de grande importância no desenvolvimento da psique feminina.

A escolha por investigar a experiência amorosa especificamente feminina partiu do pressuposto de que essa experiência se dá de forma diferenciada daquela do desenvolvimento masculino. Na mulher, o amor configura-se como um rito iniciático que a coloca na jornada da individuação, já o homem, no decorrer de seu desenvolvimento, depara-se com outras formas de iniciação.

No desenvolvimento feminino, a relação amorosa com o pai - e, posteriormente, com outros homens - tem a função de lançar a mulher em uma trajetória iniciática, tirando-a do mundo matriarcal e fazendo-a entrar em contato, através do outro, com seu processo de individuação, entendendo individuação como "o processo mais ou menos consciente de desenvolvimento psíquico, natural e dado a cada ser humano com vistas à ampliação da consciência e ao amadurecimento da personalidade" (Jacobi, 1957, p. 102).

Por meio de observações dos atendimentos clínicos e das vivências sociais e de uma revisão de literatura de autores do corpo junguiano - o próprio Carl Gustav Jung, Aldo Carotenuto, Erich Neumann, James Hillman, entre outros -, a pesquisa analisou a experiência amorosa como rito de passagem para o caminho da individuação feminina, explorando mais especificamente o sofrimento enquanto marca principal desse rito. $O$ mito de Eros e Psiquê também foi fonte para a análise aqui desenvolvida.

\section{A experiência amorosa}

Para Grizolia (2008), os arquétipos são elementos constitutivos da

[...] base de comportamentos de padrões universais, originários e instintivos, portanto não aprendidos. São herdados da natureza e estão presentes em todo tempo e lugar, porém não são passíveis de representação imagética, sendo perceptíveis para a consciência apenas pelo seu efeito em imagens e motivos arquetípicos. Eles estruturam ações, reações, pensamentos e sentimentos, porém o que 
é herdado não são as imagens propriamente ditas e sim a capacidade de termos tais imagens (Grizolia, 2008, pp. 21-22).

Ainda com base em Grizolia (2008), o Self trata-se de um fenômeno mediado pela constelação da sizígia, isto é, mobilizado pelas imagens evocadas pelo confronto com os arquétipos do animus (na mulher) e da anima (no homem).

Para Jung, o Self ou si mesmo é o centro e também a circunferência completa que compreende ao mesmo tempo o consciente e o inconsciente: é o centro dessa totalidade. $O$ corpo aparece como tradutor dos símbolos do Self, como mediador e delimitador do dentro e fora (Grizolia, 2008, p. 24).

A experiência amorosa faz parte da vivência humana e o que se experimenta durante esse processo parece ser algo tão potente que aproxima o humano do divino, em um movimento no qual o sujeito é tomado de forma tão intensa pela experiência amorosa que parece ser levado ao contato direto com o arquétipo do Self.

O tema da experiência amorosa está presente maciçamente no cotidiano de nossas vidas. Afinal, quem nunca se viu arrebatado por um objeto amoroso? E quando falamos sobre experiência amorosa, parece não haver melhor forma de tradução do que a das artes. Basta um olhar mais atento para as produções artísticas e veremos claramente a presença do tema inspirando boa parte do que é feito. No que diz respeito à literatura, isso se torna ainda mais visível, pois o tema da experiência amorosa é presença certa na maioria obras.

Na música são milhares os exemplos de composições que tratam da experiência amorosa, como a canção "Como dizia o poeta", de Albioni, Toquinho e Vinicius de Moraes (1971), em que eles poetizam e cantam a experiência do apaixonar-se como necessária ao próprio desenvolvimento:

\section{Quem já passou por essa vida e não viveu, \\ Pode ser mais, mas sabe menos do que eu. \\ Porque a vida só se dá pra quem se deu, \\ Pra quem amou, pra quem chorou, pra quem sofreu.}

Partindo dessa linha, encontramos em Carotenuto (1994), que se ocupou de pesquisar o tema, uma explicação bastante plausível para a necessidade da dimensão simbólica na expressão de vivências como a da experiência amorosa: "As vivências profundas que emergem dos recessos da nossa consciência não podem ser traduzidas na linguagem do cotidiano, somente através da função poética esses conteúdos encontram uma realização expressiva na dimensão simbólica" (Carotenuto, 1994 p. 20).

Trata-se aqui de algo que está no campo da abstração, dos sentimentos, daquilo que fica da experiência, mais do que a vivida: a experiência sentida. Isso porque a vivência amorosa funciona como um chamado para a alteridade, alerta para a importância que essa instância denominada "o outro" tem sobre a nossa subjetividade. 
Captar os mil matizes cambiantes com que encontramos o outro, penetrar no labiríntico mundo imaginário, significa abandonar toda perspectiva unilateral, para dar voz a todos os "daimones" que nos habitam. Nessa viagem misteriosa através do amor cada um encontra o outro e, por trás do outro, a si mesmo (Carotenuto, 1994, p. 27).

Para o amante, o outro-amado é sempre único, e parece haver uma necessidade psíquica de que seja exatamente aquele. A frase de Montaigne (1580/2000, p. 221) : "Se insistirem para que eu diga porque o amava, sinto que o não saberia expressar senão respondendo: porque era ele; porque era eu", - que, embora tenha sido dita quando se referia a sua grande amizade com la Boétie, serve aqui para revelar a especificidade do encontro com o outro.

Essa é uma particularidade existente no amor: há uma escolha involuntária da pessoa amada. O tema da projeção surge aqui, mas não se trata da projeção do ponto de vista freudiano, segundo o qual, projetar conteúdos sobre o outro é apenas um mecanismo de defesa. Portanto, não estamos falando de um conteúdo pulsional reprimido, modificado e deslocado para um objeto externo. Referimo-nos à projeção do ponto de vista junguiano, onde os aspectos projetados sobre o outro dizem respeito a um processo natural da psique:

Em tais casos é frequente ver que o objeto oferece uma oportunidade de escolher a projeção, ou mesmo a provoca. Isto acontece quando o objeto (pessoa) não está consciente da qualidade projetada. Com isto ela atua diretamente sobre o inconsciente do interlocutor. Com efeito, qualquer projeção provoca uma contra projeção todas as vezes que o objeto não está consciente da qualidade projetada sobre ele pelo sujeito (Jung, 1928/1984, pp. 225-226).

A partir dessa definição, retornamos à frase de Montaigne (1580/2000), pois, no caso da experiência amorosa, o ser amado está carregado de projeções. Quase sempre há um elo entre o conteúdo projetado e a tela na qual a projeção aconteceu, isto é, aquilo que foi projetado coincide, na maior parte das vezes, com as particularidades do objeto amoroso.

Além da coincidência entre objeto amoroso e conteúdo projetado, o que chama mais a atenção é a semelhança existente entre o que foi projetado e partes do próprio sujeito-amante, inicialmente experimentadas por meio da relação com o outro, mas que podem, no decorrer do relacionamento, serem reconhecidas pelo sujeito-amante como partes de sua própria psique. Dessa forma, é inevitável que durante a experiência amorosa conteúdos de ambas as partes sejam ativados, trazendo à cena anima e animus.

Sobre esse tema, Alvarenga (2017), traz uma leitura atual e pertinente, considerando as ideias de Jung e Hillman: 
Seja pela formulação primeira de Jung, seja pela proposição de Hillman, a anima e o animus expressam, inegavelmente, o primeiro momento em que a criatura experimenta o fascínio de se saber diante do milagre da descoberta da presença do outro, presença insólita, presença imperiosa que invade a psique tornando tudo o mais secundário; presença que exige dedicação plena, rendição total; presença que a criatura identifica, ou melhor, sente, intui como necessária, complementar de si; presença que inebria, enleva, embala. Presença confusionante [...] (Alvarenga, 2017, pp. 21-22).

Alvarenga (2017) chama a atenção para as características presentes no encontro amoroso, que o torna único e diferente de qualquer outro encontro humano. Define tais características como emergência anímica.

Quando os arquétipos da anima e do animus se apresentam, o humano se deslumbra. Quando a imagem arquetípica se revela aos olhos, o humano se sente possuído. Quando o símbolo constela o campo da consciência, impõe-se como realidade tão fulgurante que o Eu se queda em ato de veneração. A vivência experimentada é a de se estar na presença do divino (Alvarenga, 2017, p. 23).

Estamos diante, portanto, de um fenômeno humano, mas preponderantemente ativador de aspectos psíquicos capazes de promover uma vivência primordial arquetípica. Uma vez que anima e animus estejam ativados, conteúdos de um e de outro poderão criar um terreno bastante fértil para elaborações significativas de ambas as partes. Teoricamente, esse seria o melhor cenário, porém, na realidade, nem sempre acontece dessa forma, pois, entre o início da projeção, a retirada dela e a subsequente introjeção dos conteúdos projetados, o drama estará dado e o indivíduo poderá vivenciar as mais diversas experiências, inclusive de profundo sofrimento.

Não obstante a pretensão racional do Eu de compreender, de apreender e controlar sempre tudo, nesses casos, quando as expectativas não coincidem com a realidade, o indivíduo não pode evitar ser tomado de pânico, de dor, de um sofrimento que se torna quase físico. E é nesse momento, na dor, que a ausência do outro provoca, na ferida que o objeto de amor inflige, na violência do desejo que só o amado consegue suscitar, que o amante percebe imprevistamente que está vivo (Carotenuto, 1994, p. 35).

Esse sofrimento tem sua razão de ser, considerando-se que, no decorrer da experiência amorosa, o indivíduo entrará em contato com conteúdos que ainda não havia tocado, e a força pela qual este contato se impõe marca a experiência como sendo de alta profundidade e transformação. "O estado de enamoramento é caracterizado justamente pela ruptura violenta do próprio núcleo defensivo narcisista: o sujeito é arrancado da sua solidão para tornar a estar em contato com aspectos vitais de si mesmo, até então removidos"(Carotenuto, 1994, p. 35). 
Se é o que fere, sem dúvida, também é o que faz crescer, uma vez que é impossível sair da experiência amorosa sem que algum tipo de transformação tenha se dado. $O$ contato com conteúdos internos provocados pelo encontro com o outro é potente o bastante para empurrar o sujeito rumo a um processo de transformação. Nas palavras de Jung: "o amor no sentido da concupiscentia [sic] é a mais infalível dimensão dinâmica que traz o inconsciente à luz" (Jung, 1954, p. 86 citado por Carotenuto, 1994, p. 49).

Dito isto, talvez se torne mais claro que há um processo sendo guiado pelo próprio Self durante a experiência amorosa.

Tendo visto a importância dada à experiência amorosa como grande responsável pelo desencadeamento de processos internos, passamos agora ao questionamento que deu origem a este trabalho: qual a diferença da experiência amorosa para homens e mulheres e por que para a mulher esta experiência torna-se ainda mais profunda e transformadora?

\section{0 rito iniciático como processo de desenvolvimento psíquico}

Ao tratarmos da experiência amorosa como rito de passagem, faz-se necessário definir o que vem a ser o rito de passagem ou rito iniciático, já que está sendo utilizado um termo que diz respeito à organização das sociedades tribais, mas que, por isso mesmo, mantém-se na base de nossa constituição humana e que passou a ser utilizado pela psicologia justamente pelo seu caráter arquetípico.

A primeira referência a ser apresentada vem de Eliade (1949/1992):

O termo iniciação no sentido mais geral designa um corpo de ritos e ensinamentos cujo objetivo é produzir uma modificação radical do estatuto religioso e social da pessoa que vai ser iniciada. Em termos filosóficos, a iniciação é equivalente a uma mutação ontológica da condição existencial. $\bigcirc$ noviço emerge da sua provação como um ser totalmente diferente: tornou-se outro (Eliade, p. 137).

Aqui importa reconhecer o caráter de transformação que a experiência da iniciação provoca no individuo principalmente no âmbito psíquico.

É Jung (1961/2008) quem faz a leitura da iniciação enquanto um arquétipo de extrema importância no processo de constelação do ego, que traz à tona a consciência individualizada do ego no decorrer do desenvolvimento do indivíduo. Nesse processo de separação há grande possibilidade de lesões no sentido original da totalidade, o que pode ser reparado nos movimentos que o ego faz na tentativa de restabelecer as relações com o Self e assim manter a saúde psíquica.

A história antiga e os rituais das sociedades primitivas contemporâneas fornecem-nos abundante material sobre mitos e 
ritos de iniciação, nos quais jovens rapazes e moças são afastados de seus pais e obrigados a se integrarem no seu clã ou na sua tribo. No entanto, nesse rompimento com o mundo infantil, o arquétipo parental original pode ser molestado, e para que tal dano seja sanado é necessário um processo "curativo" de assimilação à vida do grupo (a identidade do grupo com o indivíduo é, muitas vezes, simbolizada por um animal totêmico). Assim, o grupo satisfaz as exigências do arquétipo que foi lesado e torna-se uma espécie de segundo pai ou mãe, aos quais o jovem é simbolicamente sacrificado, renascendo numa nova vida (Jung, 1961/2008, p. 168).

Os ritos iniciáticos quase sempre são caracterizados por práticas violentas e, não raro, há a presença de mutilações, entorpecimentos, fome, solidão, exposição ao relento, cegueira, ou seja, o sujeito é levado a um estado de iminência da morte, ainda que simbólica. Essas vivências de dor não acontecem por acaso, elas são guiadas pelas mãos da necessidade, pois somente a partir do sofrimento a passagem pode ser inscrita com alguma garantia de que a regressão ao estágio anterior não acontecerá.

Nessa "cerimônia drástica que lembra muito um sacrifício oferecido às forças que podem reter um jovem", segundo expressão de Jung, vemos que o poder do arquétipo original nunca pode ser totalmente dominado, como acontece nas lutas herói-dragão, sem um mutilante sentimento de alienação em relação às fecundas forças do inconsciente.

Em nossa cultura, o desenvolvimento necessário, através do qual a criança emerge da relação primal para alcançar maior independência, corresponde a uma transição do matriarcado psicológico, no qual o arquétipo da mãe é dominante, para o patriarcado psicológico, no qual domina o arquétipo do pai (Neumann, 1980, p. 79).

Esse embate que caracteriza a saída bem sucedida do matriarcado, descrito por Neumann, pode ser comparado ao que na psicanálise é tida como a saída bem sucedida do complexo de Édipo.

É importante ressaltar que a leitura de Neumann (1980) serve apenas para compreender o processo de formação da consciência, pois, atualmente, muito se tem produzido sobre a formação do feminino e do masculino. Para não incorrer no risco de utilizar uma leitura ultrapassada, citamos Lazdan (2015):

A leitura da Psicologia Analítica sobre as relações de gênero, por meio de seus conceitos como anima, animus, persona, sombra e processo de individuação, nos possibilita uma articulação pertinente e atual com as reformas masculinas e configurações de relacionamento contemporâneas. Esta vertente psicológica nos mostra $\circ$ quanto as transformações sociais reverberam nas dinâmicas psíquicas individuais, impulsionando o indivíduo ao 
encontro com os próprios complexos arquetípicos paralelamente aos seus encontros e arranjos amorosos na vida. Um relacionamento afetivo entre dois indivíduos ocorre sempre em ressonância com o relacionamento psicológico despertado em cada membro (Lazdan, 2015, pp. 53-54).

Assim, essa primeira passagem que o indivíduo enfrenta pode ser considerada como inaugural nos ritos de passagem que virão no decorrer da vida. Vale destacar que não é exatamente depois da saída do matriarcado e da entrada no patriarcado que os caminhos do processo de individuação de homens e mulheres irão se diferenciar.

rito iniciático, enquanto uma passagem de um estado a outro, não se dá somente na infância ou na juventude, mas também no decorrer da vida e das experiências, quando nos deparamos com novos ritos, novas passagens, dinâmicas que vivenciamos frequentemente. A questão é que, atualmente, esses ritos ou momentos de transformação não parecem ter a mesma força de outrora.

Para Lima Filho (1997), a falta de demarcação de uma fase de desenvolvimento para outra pode trazer consequências danosas ao desenvolvimento.

Uma das consequências da tênue demarcação de fases do desenvolvimento é seu prolongamento para além do que seria necessário, desejável e saudável. Os inícios e os fins se diluem, se confundem e, em decorrência disso, o significado psicológico e o senso de responsabilidade ligados a cada estágio ficam igualmente vagos, imprecisos, mal percebidos, mal integrados (Lima Filho, 1997, p. 141).

Embora tenhamos nos deparado com a questão acima, o que parece permanecer e continuar atuando fortemente em nossa sociedade é o mito do herói, enquanto possibilidade de construção e estruturação do eu e, principalmente, enquanto estruturação da personalidade baseada na separação entre o consciente e o inconsciente.

Partindo desse pressuposto, consideramos que a primeira fase do desenvolvimento não difere muito no que tange a meninos e meninas. Mas, com a entrada no mundo patriarcal, ambos os caminhos vão se distinguir significativamente, assim como as experiências e possibilidades de desenvolvimento se diferenciam no decorrer do desenvolvimento de cada um.

mundo patriarcal poderá continuar exigindo desse homem uma atitude heroica. No caso da mulher, essa experiência parece não ser a marca principal. Do ponto de vista psíquico, a mulher adentra o mundo patriarcal e nele permanece ainda de forma ingênua, ou seja, a consciência está voltada aos valores puramente patriarcais e ela irá se desenvolver a partir destes valores. Pode-se considerar que essa dinâmica não oferecerá a ela os recursos para o exercício pleno de sua feminilidade. 
A fim de compreender melhor essa trajetória típica, algumas teóricas desenvolveram linhas de pensamento que podem nos servir de referência para marcar as passagens no processo de desenvolvimento feminino, o que não foge completamente do modelo heroico, mas traz diferenças significativas nos processos de homens e de mulheres.

Lima Filho (2002) apresenta Maureen Murdock e Annis Pratt como dois exemplos de teóricas femininas, dentro do campo da psicologia, que se propuseram a pensar a jornada da heroína, enfatizando justamente um percurso voltado aos valores femininos.

Como terapeuta de mulheres, Murdock encontrou insatisfação feminina frente ao sucesso no mercado: um senso de esterilidade, vazio, desmembramento e traição. Foram mulheres que abraçaram a jornada heroica masculina, saíram bem-sucedidas, mas exauridas e sofridas, com seus corpos e almas sacrificadas (Lima Filho, 2002, p. 191).

$[\ldots]$

Murdock reafirmou sua crença de que as mulheres têm uma busca a empreender: a aprendizagem de valorizar-se como mulheres e curar a ferida do feminino (p. 3). Procurou delinear o caminho da heroína: nada fácil; não há mapas, nem idade cronológica para começar; é tortuoso; raramente recebe validação externa, chegando a ser sabotado e impedido. Sua referência da jornada heroica feminina deriva em parte do modelo de Campbell. Porém, a linguagem em que é formulada é específica para as mulheres, e o desenho que a representa é um caminho circular que gira no sentido relógio (Lima Filho, 2002, p. 192).

Se Murdock, ainda seguindo o modelo de Campbell, já apresenta diferenças significativas no percurso traçado pela mulher em seu desenvolvimento, Annis Pratt aprofunda essa ideia na medida em que estabelece um modelo diferenciado de busca do feminino.

Annis Pratt (1994, p. 205-209)[sic], por sua vez, estudou a ficção de autoras inglesas e americanas. Descobriu indícios de uma possibilidade feminina mais holista e subversiva. Nos romances de transformação e renascimento, que podem servir como catalisadores de escolhas existenciais, identificou uma maturação psicológica mais completa. Romancistas e poetisas advertem sobre os horrores patriarcais e proporcionam momentos de epifania, quando se ergue das profundezas uma qualidade feminina que transcende [...] as polaridades de gênero, destruidoras da vida humana (p. 209). Pratt concluiu que a busca social da heroína implica estágios diferentes dos que Campbell e outros descreveram para o herói masculino e identifica dois tipos de busca: - a busca social, realizada pela mulher jovem, definida como uma busca pelo Si-mesmo, em que a 
protagonista começa na alienação e vai em busca da integração no seio de uma comunidade humana onde possa desenvolver-se mais plenamente; - a jornada de renascimento, empreendida não antes da segunda metade da vida, definida como busca de relação com o poder ou poderes cósmicos (Lima Filho, 2002, pp. 193-194).

A partir dos modelos alternativos de processo de desenvolvimento feminino, que o diferencia do masculino, pode-se observar o quanto os aspectos do mundo feminino e a contraposição aos valores patriarcais estão presentes. Essa perspectiva nos ajuda a seguir por um caminho no qual as experiências que irão marcar o processo de desenvolvimento psíquico feminino fogem da lógica patriarcal e, mais do que isso, subvertem a ordem e é justamente na subversão que está a possibilidade de libertação.

\section{A experiência amorosa como rito de passagem dentro do processo de individuação feminino}

percurso feito até agora nos ajudou a separar a experiência de desenvolvimento psíquico feminino da experiência masculina. Iniciando com uma aproximação, quando ambos, meninos e meninas, rompem com o mundo matriarcal para adentrar o mundo patriarcal e, em seguida, apresentando a trajetória do homem como atuante do mito do herói e como aquele cuja matriz identitária está associada ao universo paterno, masculino, muito diferente da matriz feminina para a qual a mulher deveria retornar.

Agora retomamos à questão apresentada inicialmente: de que forma a experiência amorosa serve como rito de passagem no processo de individuação feminino?

Antes de nos aprofundarmos nessa questão, é importante situar a experiência amorosa, agora mais especificamente no campo feminino. Fala-se aqui do ponto de vista de uma experiência marcada, também, por valores patriarcais, ou seja, já muito cedo a menina é direcionada para o mundo dos amores; a ideia da menina que, desde sempre, deseja namorar está presente em nosso imaginário coletivo e se estende pelo processo de desenvolvimento feminino, no qual a cobrança por um parceiro, por um casamento, é sempre bastante forte. Tome-se como exemplo o volume de produção literária voltada ao romance, com grande parte do público-alvo marcadamente feminino. Tratase de uma ideia presente na coletividade que não deixa de ter impactos psíquicos nas individualidades.

Assim, parece que a experiência amorosa marcará profundamente a vida da mulher, instaurando uma dinâmica na qual boa parte de suas experiências virá de seus relacionamentos, o que irá compor de forma contundente o seu desenvolvimento psíquico. 
Ao explorarmos o mito de Eros e Psiquê, partindo da análise de Neumann (2017), temos o desenrolar de uma perspectiva da individuação feminina que vem ao encontro da proposta apresentada neste trabalho.

De forma geral, pode-se olhar o mito como sendo um rito iniciático vivenciado por Psiquê. A partir da descoberta do amor, todo o processo que segue vai marcando a trajetória da saída do mundo inconsciente para o mundo da consciência. Neste processo, cada ação está carregada de um sentido muito particular de experimentação do mundo.

Inicialmente temos a figura de Psiquê sendo levada ao casamento com um monstro terrível, como o resultado da punição dada por Afrodite por ela ter chamado a atenção para si por tanta beleza, afrontando, assim, a deusa magnânima. Tal fato já demonstra o caráter ritual no qual se inicia o mito, a passagem de um estado a outro já é sinalizada. Sobre esse ponto Neumann (2017) escreve:

Desta maneira, o efeito arquetípico das núpcias de morte das donzelas da antiga época matriarcal, passando pelo sacrifício da donzela no ritual da consumação do casamento, chegou até a época moderna. $O$ tema das núpcias de morte ocupa a posição central do mito de Psiquê, se bem que, no início, ele pareça ser uma mera vingança de Afrodite (Neumann, 2017, p. 86).

Há importantes aspectos do mito a serem considerados aqui, um deles diz respeito justamente ao que se passa no interior de Psiquê, pois, embora ela afirme ao amante que não lhe desobedecerá, em momento algum abre mão de ouvir suas irmãs, figuras que representam um aspecto salutar de Psiquê, com um importante papel na sua tomada de consciência.

Psiquê ignora a "aparência verdadeira" de Eros, seu amante, e há tempos a oposição monstro-amante vivia no seu inconsciente, sem ter alcançado a consciência; mas foram exatamente as irmãs que a conscientizaram do presumível aspecto da "fera mortal". Com isso, Psiquê entra em conflito aberto no que se refere ao seu relacionamento amoroso consciente, no qual Eros é seu consorte. Não é mais possível continuar no seu estado de inconsciência. Ela tem de ver o aspecto real do parceiro e, apesar da ambivalência, a oposição entre a Psiquê que odeia o monstro e ama o marido se projeta para o exterior e ela é obrigada a entrar em ação (Neumann, 2017, pp. 95-96).

Chama-se a atenção para a importância do momento em que Psiquê resolve ver o amado sob a luz, o que pode ser considerado uma marca, onde há a transformação psíquica, ou seja, ao encontrar-se com o outro, Psiquê tem acesso à possibilidade de mergulhar em si mesma. Aqui, lembramos da tônica do encontro amoroso:

momento decisivo do destino na vida do feminino, em que pela primeira vez - emerge do seu inconsciente a mulher - e da clausura 
da sua cadeia matriarcal, e, num encontro individual com o masculino - , ela ama, isto é, reconhece Eros (Neumann, 2017, p. 97).

Alvarenga (2017) também aborda essa temática ressaltando mais uma vez a ativação do arquétipo. Em sua abordagem, considera que anima e animus serão ativados tanto na mulher como no homem. Como aqui refere-se mais ao universo feminino, cabe o seguinte:

Nas relações anímicas amorosas a mulher fascinada com a figura de um homem (expressão simbólica do animus) tem seu próprio complexo-anima ativado. Assim sendo, mesmo desejosa de ser cuidada, permanece com seu próprio complexo-animus que a protege contra a perda de sua própria liberdade (Alvarenga, 2017, p. 50).

Assim, atenta-se para a profundidade da experiência feminina do encontro, pois, ao deparar-se com o amor, a experiência do encontro com o outro a coloca em contato com aspectos muito particulares, da própria essência do feminino. É a saída do estado de ingenuidade para um estado de maior autonomia - há o ganho nítido de consciência.

O encontro amoroso é uma experiência arquetípica, como afirma Moraes (2000). Esta afirmação significa que as formas externas desse encontro podem ser as mais variadas, mas em essência, representa sempre a busca pela completude através do parceiro que representa o "outro" desconhecido dentro de nós (Parisi, 2009, p. 41).

Portanto, estamos tratando o encontro amoroso no campo da experiência arquetípica. Assim, na figura de Psiquê encontramos a própria alma feminina em processo de transformação. Isso fica claro logo que Psiquê, tomada pela experiência do encontro, é lançada ao processo. É aqui que o rito iniciático ganha seu sentido, já que sua trajetória se dará individualmente, uma vez que, nesse momento, o amado Eros se distancia, marcando a necessidade de a jornada de Psiquê ser individual.

Algo nesse processo parece se tornar claro: a tendência inconsciente de se tornar consciente, o que, de certa forma, nos faz retornar à experiência inicial de separação, ou seja, parece haver uma tendência própria da psique para a construção da consciência.

A ação de Psiquê rompe a "participação mística" (ou um estado de união total onde não cabe diferenciação), o que torna inevitável a separação dos amantes, marcada pelo nascimento da consciência. "O amor como expressão do feminino não acontece nas trevas, como um processo simplesmente inconsciente; um encontro legítimo com o outro envolve a consciência, a despeito da separação e do sofrimento" (Neumann, 2017, p. 105). 
É no cumprimento das tarefas que Psiquê recebe de Afrodite que se dará o desenvolvimento de seus recursos interiores, possibilitando-lhe encontrar em si mesma a capacidade de enfrentamento - não de uma forma heroica, masculina, mas podendo acessar e se apropriar de seus recursos, suas capacidades, potências tipicamente femininas.

Vale destacar a função da quarta tarefa, da descida ao Hades, onde Psiquê entrará em conflito direto com o princípio feminino central, com AfroditePerséfone. No mito, essa mostra-se como a tarefa principal ou a mais difícil, mas também é justamente a que a liberta, apesar da presença do sofrimento.

Não há como não pensar na experiência amorosa enquanto vivência de sofrimento. Ainda que se trate de uma experiência bem sucedida, na qual há reciprocidade, a dor poderá estar presente quando na ausência do outro. Tal sofrimento é ainda mais marcante quando não há reciprocidade de sentimentos, quando o outro que se deseja não está disponível.

Não obstante a pretensão racional do Eu de compreender, de apreender e controlar sempre tudo, nesses casos, quando as expectativas não coincidem com a realidade, o indivíduo não pode evitar ser tomado de pânico, de dor, de um sofrimento que se torna quase físico. É nesse momento, na dor que a ausência do outro provoca na ferida que o objeto de amor inflige, na violência do desejo que só o amado consegue suscitar, que o amante percebe imprevistamente que está vivo (Carotenuto, 1994, p. 39).

Tal dificuldade se expressa principalmente quando, na vivência de uma experiência amorosa, a mulher adere à figura do amado e isso não lhe permite enxergar a si mesma, correndo o risco de não prosseguir em seu caminho de individuação. A consciência que ganhara até então, fica presa no amor que se direciona unicamente para o outro, sem a possibilidade de continuar alimentando a busca individual. Podemos enxergar essa prisão como um retorno aos ditames do inconsciente, uma vez que ela parece repetir uma experiência de união indiscriminada, sendo a figura do amado um provável substituto à tirania do casal parental.

É nesse momento que a vivência do sofrimento ganha um significado marcante e profundo, capaz de lançar a mulher ao mundo inferior, e essa descida passa, então, a ter o caráter de uma morte simbólica. A dor e o sofrimento experimentados são a matéria principal a colocá-la diante de si mesma.

Em termos alquímicos, podemos ampliar a compreensão com a imagem da nigredo, como bem coloca Hillman (2011):

A psicologia alquímica nos ensina a entender como realizações os períodos infrutiferamente amargos e secos, as melancolias que parecem não ter fim, as feridas que parece não sarar, as opressivas e sádicas mortificações da culpa e a putrefação do amor e das amizades. Estes são começos por serem fins, dissoluções, desconstruções. Mas não são o começo, como uma ocorrência 
única no tempo. Tal seria uma leitura literal do processo alquímico que não é um modelo unidirecional, progredindo com o tempo. É uma iteratio; o preto se repete para que a desconstrução continue (Hillman, 2011 , pp. 137-138).

Desse modo, o que temos é um processo de luto, melancolia, do próprio deprimir, muitas vezes, a experiência de um vazio imenso, mas que também pode ser visto como possibilidade, afinal, é justamente no vazio que cabe tudo, ou é no vazio que há espaço pra que o novo possa surgir.

Para Jung (1912/1916), a depressão representa um esvaziamento da libido na consciência o que leva a um acúmulo de energia no inconsciente. Através do sistema de autorregulação da psique ocorre uma introversão involuntária como forma de compensação a uma atitude unilateral da consciência: há um esvaziamento de energia no ego que pode se manifestar como depressão. Se os conteúdos do inconsciente forem assimilados e integrados há uma renovação e transformação da consciência. A depressão vista desta forma não é necessariamente patológica e está associada ao processo de transformação da personalidade (Parisi, 2009, p. 56).

Nesse sentido, verificamos que muitas mulheres experimentam a depressão como parte da experiência amorosa. $\bigcirc$ estado em que se encontram quando chegam ao consultório para iniciar a psicoterapia não é o início do processo, a nigredo já começou anteriormente, a depressão veio com a desilusão ou com a perda do objeto de amor. Estão no momento de descida, de visita ao Hades, de passagem por ele, como faz Psiquê no mito. Há o sentimento de perda de sentido, uma vez que o objeto amado era depositário das projeções do animus e da alegria de viver. Nas palavras do próprio Jung (1951/2013), "só se pode conhecer a realidade da sombra, em face de um outro, e a do animus e da anima, mediante a relação com o sexo oposto, porque só na relação a projeção se torna eficaz" (Jung, 1951/2013, p. 35).

Com isso em vista, interessa-nos compreender melhor a natureza do animus e de que forma esse arquétipo atua na psique feminina, podendo, inclusive, torná-la prisioneira desse complexo ativado. "Ela pode ter sua vida criativa paralisada, vítima de uma autocritica feroz que a imobiliza e impede de realizar seus potenciais no mundo" (Parisi, 2009, p. 28).

Observa-se esse drama sendo encenado cada vez que, em uma experiência amorosa, a mulher experimenta uma relação onde o outro torna-se motivo de aprisionamento e de dependência, fazendo com que muitas mulheres percam a dimensão de individualidade e autonomia, ou seja, perdem-se a si mesmas.

Podemos pensar ainda que o estabelecimento de padrões de relacionamentos aprisionadores pode guardar uma estreita relação com a forma como o próprio animus foi sendo constelado a partir das experiências das mulheres com seus pais. Aqui estamos nos referindo ao conceito de complexo, que pode ser entendido como um "conjunto de sentimentos, pensamentos, crenças, ideias, memórias e afetos, que tem em seu núcleo um conflito inconsciente, 
que acaba por gerar comportamentos patológicos e, consequentemente, podem acarretar sintomas" (Grisolia, 2008, p. 27).

Tendo em vista a ideia de complexo psíquico, pode-se supor que sintomas neuróticos, nos quais o sofrimento amoroso é constante e repetitivo, possam ter como base um relacionamento negativo com objetos masculinos originários, o pai, por exemplo. Tal complexo pode facilmente orientar, de forma patológica, a maneira como algumas mulheres lidam com suas perdas amorosas e se dispõem a relacionamentos tóxicos, em uma tendência compulsiva a curar, anistiar ou deixar-se maltratar por possíveis amantesalgozes.

Portanto, a vivência da experiência amorosa como uma forma de dor, aprisionamento, descida ao Hades, nigredo, depressão, pode justamente servir de passagem. Aqui, cabe retomar o conceito de rito como ato que inscreve no corpo, na carne da vida, a experiência simbólica. Assim, passar pela experiência de sofrimento amoroso é um modo de inscrever a morte simbolicamente, o que abre espaço para o surgimento da uma vida nova.

O sofrimento, qualquer que seja, permanece como condição de ser insuportável se o mesmo se mantiver eternamente alheio à própria identidade, como corpo estranho. A dor deixa de ser insuportável quando pode ser elaborada e, na condição de símbolo estruturante, passar a compor identidade, transformando-se em realidade integrante da totalidade do indivíduo. A dor torna-se suportável quando, pela transformação, se faz símbolo estruturante da própria identidade (Alvarenga, 2017, p. 15).

No sofrimento amoroso, há sempre uma oportunidade sendo oferecida, uma dádiva oculta sob os véus doloridos do amor. Seguindo esse caminho, vislumbra-se o que seria um esboço de solução, caso a mulher sofredora aproveite essa oportunidade para confrontar o seu animus e fazer dele um aliado. Nas palavras de Jung (1951/2013):

Assim o animus é também um psychopompos, isto é, um intermediário entre a consciência e o inconsciente, e uma personificação do inconsciente. Da mesma forma que a anima se transforma em um Eros na consciência, mediante a integração, assim também o animus se transforma em um Logos; da mesma forma que a anima imprime uma relação e uma polaridade na consciência do homem, assim também o animus confere um caráter meditativo, uma capacidade de reflexão e conhecimento à consciência feminina (Jung, 1951/2013, p. 29).

Chegamos, portanto, ao ponto crucial da vivência amorosa feminina, quando ela, conduzida por uma consciência devidamente "rematriciada" no feminino e por seu animus, consegue fazer a passagem do estado de ingenuidade, imaturidade, de grande dependência do outro para um estado de autonomia, de posse de si mesma. Não se trata do feminino da Grande Mãe, mas de um 
feminino autêntico, construído a partir de suas próprias experiências. Ou seja, estamos falando da própria individuação.

Nesse ponto, voltamos a Neumann (2017) e ao mito de Eros e Psiquê, até como forma de concluir a ideia iniciada anteriormente:

A experiência que Psiquê tem da unidade do Grande Feminino não é a experiência primitiva dos opostos na sua unidade numinosa urobórica, mas a experiência da totalidade, que a mulher vive na sua individuação como um resultado do próprio aperfeiçoamento (Neumann, 2017, pp. 158-159).

E mais do que isso, quando Psiquê resolve, por conta própria, abrir a caixa que continha a beleza imortal, ela se apropria e singulariza o próprio desejo, ela comete o seu ato heroico muito particular, pois atreveu-se a desobedecer a ordem de Afrodite. Nisso reside a grande possibilidade de Psiquê se diferenciar. Há uma ousadia e uma autonomia em seu ato, pois com isso pode se aproximar do que Neumann (2017) chama de "Self feminino".

Na medida em que Psiquê se comporta de forma tão paradoxal nesse ponto, ela torna a unir-se ao próprio centro feminino do self. Ela professa seu amor e agarra-se ao encontro individual com Eros e ao mesmo tempo prova que todo o seu juízo - masculino - é primordialmente feminino. A ênfase masculina com a qual teria de ter percorrido seu caminho é eliminada através da sua feminilidade, e nos parece que justamente pelo toque feminino, sem saber e sem querer, ela obtém o perdão de Afrodite-Perséfone (Neumann, 2017, pp. 151-152).

Por fim, temos agora delineado um caminho de individuação feminino bastante particular, que o diferencia substancialmente da experiência masculina. Situar a experiência amorosa no universo feminino e poder enxergá-la do ponto de vista do desenvolvimento psíquico é também oferecer outra possibilidade de reconhecer a própria experiência amorosa como material a ser transformado nesse processo de reencontro com o feminino.

Isso significa também enxergar o feminino, dentro do mundo patriarcal, como possibilidade de libertação e de autonomia.

\section{Considerações finais}

O desenvolvimento psíquico feminino percorre caminhos diversos daqueles do masculino. Essa é uma das possíveis diferenças que procuramos discutir neste trabalho. Se para o homem o momento decisivo de saída do mundo inconsciente para o mundo consciente é marcado por seu embate com o dragão e por sua trajetória como herói, para a mulher, a saída do mundo inconsciente se dará de forma marcante, por meio do embate com seu próprio animus, quando a leva para o mundo inferior. Mas, diferentemente do rapto de Perséfone, o que tentamos destacar aqui foi o caráter de iniciação que a 
experiência amorosa vem significar no desenvolvimento psíquico feminino. Ao utilizar a figura de Psiquê, intentamos marcar que todo o seu trajeto na busca pelo amor de Eros é, na verdade, a busca por si mesma, para tornar-se inteira e, então, relacionar-se com o outro.

Acreditamos que esse seja um ganho dentro do universo feminino, principalmente enquanto possibilidade de autoconhecimento e de valorização como mulher dentro de uma sociedade patriarcal. Também há um ganho coletivo, uma vez que o processo de desenvolvimento psíquico por meio da experiência amorosa passa a fazer parte da consciência coletiva, estendendose a toda a sociedade, atuando principalmente nas relações entre homens e mulheres.

Voltando ao mito de Eros e Psiquê, é justamente a ousadia da atitude de Psiquê em seguir o próprio desejo que liberta Eros e, então, o amor pode ser vivido de forma liberta, inclusive sendo reconhecido por Afrodite.

Portanto, ao adquirir consciência, ao colocar-se em seu próprio caminho de individuação, a mulher pode inserir no mundo outra ordem, que não mais diz respeito aos opostos enquanto antagônicos, mas como busca pelo sentido de alteridade.

\section{Referências}

Albioni, T., Toquinho, Moraes, V. ([1971]). Como dizia o poeta [Gravado por Marilia Medalha, Toquinho, \& Vinícius de Moraes. In Como dizia o poeta...: música nova. Rio de Janeiro: RGE. Recuperado de http://www.toquinho.com.br/album/lp-como-dizia-o-poeta-musica-nova/.

Alvarenga, M. Z. (Org.). (2017). Anima-animus de todos os tempos. São Paulo: Escuta.

Carotenuto, A. (1994). Eros e pathos: amor e sofrimento. São Paulo: Paulus.

Eliade, M. (1992). Origens: história e sentido na religião. Lisboa: Edições 70. (Trabalho original publicado em 1949).

Grizolia, L. M. (2008). Paixão como projeção: quando esse sentimento aprisiona Trabalho de Conclusão de Curso, Pontifícia Universidade Católica-SP, São Paulo.

Hillman, J. (2011). Psicologia alquímica. Petrópolis, RJ: Editora Vozes.

Jacobi, J. (1957). Complexo, arquétipo e símbolo na psicologia de C. G. Jung. São Paulo: Cultrix.

Jung, C. G. (1984). Aspectos gerais da psicologia dos sonhos. In A natureza da psique. (OC, Vol. VIII/2, pp. 186-234). Petrópolis, RJ: Vozes. (Trabalho original publicado em 1928).

Jung, C. G. (Org.). (2008). O homem e seus símbolos. 10 ed. Rio de Janeiro: Nova Edição. (Trabalho original publicado em 1961). 
Jung, C. G. (2013). Aion: estudos sobre o simbolismo do si-mesmo. (OC, Vol. IX/2, 10 a ed.). Petrópolis, RJ: Vozes. (Trabalho original publicado em 1951).

Lazdan, A. M. (2015). O que os homens têm a dizer sobre as mulheres: os novos posicionamentos de jovens do gênero masculino frente às transformações femininas nas relações afetivas: uma leitura sob a ótica da psicologia analítica. Dissertação de Mestrado, Faculdade de Ciências e Letras, Universidade Estadual Paulista Júlio de Mesquita Filho, Araraquara.

Lima Filho, A. P. (1997). Brincadeiras selvagens problema nosso: Diálogo com pais de adolescentes. São Paulo: Oficina de textos.

Lima Filho, A. P. (2002). O pai e a psique. São Paulo: Paulus.

Lispector, C. (1998). A hora da estrela. Rio de Janeiro: Rocco, 1998. (Trabalho original publicado em 1977).

Montaigne, M. (2000). Os Ensaios (R. C. Abílio, trad.). São Paulo: Marins Fontes. (Trabalho original publicado em 1580).

Neumann, E. (1980). A criança: estudo e dinâmica da personalidade em desenvolvimento desde o início da sua formação. São Paulo: Cultrix.

Neumann, E. (2017). Eros e Psiquê. Amor, Alma e Individuação no Desenvolvimento do Feminino. São Paulo: Cultrix.

Parisi, S. (2009). Separação amorosa e individuação feminina: uma abordagem em grupo de mulheres no enfoque da psicologia analítica. 2009. Dissertação de Doutorado. Instituto de Psicologia, Universidade de São Paulo, São Paulo.

Minicurrículo: Ana Lúcia Cirineu - Psicóloga Clínica. Graduada em Pedagogia pela UNIFAI. Graduada em Psicologia pela Unipaulistana. Especialização em Psicologia Analítica pela OPUS Psicologia e Educação. Email: lucirineu2@hotmail.com 